American Journal of Pharmaceutical Education 2019; 83 (5) Article 7657.

\title{
COMMENTARY
}

\section{Writing from the Head and the Heart}

\author{
Gayle A. Brazeau, PhD \\ Marshall University, School of Pharmacy, Huntington, West Virginia \\ Editor, American Journal of Pharmaceutical Education, Arlington, Virginia
}

Submitted May 29, 2019; accepted June 3, 2019; published June 2019.

Keywords: manuscripts, publications, writing, head, heart

It has truly been a pleasure to continue to work with the many talented authors who submit their manuscripts to the American Journal of Pharmaceutical Education. We continue to receive many excellent manuscripts each year, with the quality of the manuscripts improving over the years. Upon reflecting on what makes a manuscript outstanding, including those papers that won the Rufus A. Lyman award, two elements come to mind: the author has used their head and their heart in preparing and writing their manuscript.

Outstanding manuscripts always have, at their core, evidence that the author has used their head (intellect) in developing and writing a story to be shared with our Academy and other health care educators. These authors have identified gaps to enhance the scholarship of teaching and learning by being aware of the current literature, using the best study design for the hypothesis, using the appropriate quantitative and/or qualitative instruments and tools, presenting the results in a logical and useful format, and analyzing the findings and their significance for the Academy. They let readers believe that the paper has advanced their knowledge. AJPE has and continues to provide authors with resources to help them be successful when writing their manuscripts. ${ }^{1-3}$

Equally important is for the authors to take the time to carefully review and follow the instructions. The editorial team of AJPE updates the instructions to authors periodically to help authors as they prepare their manuscript for submission. We are thankful for those authors who take the time to read and follow the instructions as this enables us to quickly send the manuscript out for peer review. In addition, this process helps reviewers provide important guidance back to the authors when their manuscript is accepted with major revision, or accepted with minor revision, or rejected.

Corresponding Author: Gayle A. Brazeau, Marshall University, School of Pharmacy, One John Marshall Dr., Huntington, WV 25755. Tel: 304-967-7390. Fax: 304-6967309. E-mail: brazeau@marshall.edu
Now, you might be wondering what I mean by writing from the heart when talking about scholarly peerreviewed manuscripts. Writing from the heart is putting into consideration the reviewers who volunteer to review the manuscript and share their intellect, expertise, and time. The success of advancing our scholarly efforts can only be achieved when each of us consider how we care for our colleagues and for our profession of pharmacy education. The adjective "caring" is displaying kindness and concern for others. Synonyms for caring include kindhearted, warmhearted and softhearted. The intersection of our head and heart is the foundation for our success. In reflecting about those outstanding manuscripts, there are three key characteristics of how the work of these authors embody writing from the heart.

First, these authors look at their manuscript from the perspective of the reader. The best papers leave the reader wanting more from the manuscript. The reader finds the results and conclusions exciting and can easily see how this work has advanced their role as a scholarly educator. The reader is glad that they took the time to read the paper. The reader cannot wait to share the results with their colleagues and be an advocate for the work presented in the paper. Furthermore, the reader is grateful that the paper offered critical insight into how they can solve their current challenges with pharmacy education, or the reader is grateful that the paper allowed them to think in a new direction or reflect on older ideas or thoughts. All of us at some time have read such a paper in an educational, clinical, or science-based journal.

Second, successful authors are considerate because they take the time to carefully review their manuscript to ensure that it follows the instructions to authors prior to submitting their paper. All papers submitted to AJPE now undergo a technical check/screening process and papers that fail to meet minimal requirements are returned to the authors for revision prior to being further considered for possible peer review. Considerate authors check first if they are submitting to the appropriate journal and whether their paper falls in the scope of the journal they are submitting to. To be considered for publication in AJPE, the 


\section{American Journal of Pharmaceutical Education 2019; 83 (5) Article 7657.}

manuscript must relate to pharmacy education and provide useful information for the national or international audience of AJPE. If a submission has only local or regional relevance, its usefulness to the majority of our readers is limited and, thus, will be rejected. Being considerate of the editorial team's time in weeding out submitted manuscripts whose content clearly does not fall within the scope of the journal allows the team to process accepted manuscripts for publication ahead of print or for copyediting.

Third, successful authors, prior to submitting, have taken the time to step back and look at their manuscript from the perspective of the peer reviewer. Thoughtful, considerate, and caring writers know that they need to take that final look prior to submitting their manuscript to ensure that it is ready for the peer-review process. They realize in this step the value of the gift of time the peer reviewers and editors are providing so that they can have the best manuscript possible in this initial submission or in future revisions. They also know in their head and heart if the work they presented in their manuscript really advances the Academy, or if their paper is just a way for them to get published. Good writing will not offset a poor study design, and, if the author knows the study is poorly designed, they will not take the time to prepare the manuscript. Furthermore, a critical and thoughtful look at the structure of the manuscript is a key consideration in respecting those who will be asked to provide a review. Good authors organize their manuscript well to help ease and facilitate the review process. For example, good authors think about the tables, figures and appendices and whether they can be easily reviewed such as that each table appears on a single page. Good authors make sure that symbols or lines in their figures are sufficiently large enough to convey the difference between the various treatment groups. Good authors ask someone else not involved with the study or the writing of the manuscript to read the manuscript for grammatical errors and other errors.

The combination of using one's head and heart is not novel or innovative for scholarly writing. Nelson Mandela reminds us that "A good head and a good heart are always a formidable combination. But when you add to that a literate tongue or pen, then you have something very special." Writing a scholarly manuscript is hard work even for the best authors. Successful authors in AJPE have a dedication to the causes of advancing our knowledge in the scholarship of teaching and learning and in ensuring that others can take this work as a foundation for additional work. They realize the importance of using their intellect (head) combined with their passion (heart) are the keys to success. This combination is a powerful force for staying committed despite any challenges or obstacles encountered in the writing process. The best authors always write from the head and the heart as they recognize that this powerful and formidable combination is the basis for those special and outstanding scholarly publications.

\section{REFERENCES}

1. Persky AM, Romanelli F. Insights, pearls, and guidance on successfully producing and publishing educational research. Am J Pharm Educ. 2016;80(5):Article 75.

2. Franks A. Design and evaluation of a longitudinal faculty development program to advance scholarly writing among pharmacy practice faculty. Am J Pharm Educ. 2018;82(6):Article 6556.

3. Shafeeq H, Hammond DA, Swanson JM, Li C, Devlin JW. Critical care PGY-2 graduate perceptions and practices regarding residency project publication. Am J Pharm Educ 2019;83(2):Article 6515. 